\title{
Basic Research for New Tooth Whitening Applied the Powder Jet Deposition
}

\section{Kuniyuki Izumita ${ }^{1,2 *}$, Ryo Akatsuka ${ }^{1}$, Hiroki Hihara ${ }^{1}$, Akihiko Tomie ${ }^{3}$, Chieko Kuji ${ }^{3}$, Tsunemoto Kuriyagawa ${ }^{4}$ and Keiichi Sasaki ${ }^{1}$}

${ }^{1}$ Division of Advanced Prosthetic Dentistry, Tohoku University Graduate School of Dentistry, Sendai, Japan

${ }^{2}$ Tohoku University Hospital Maxillofacial Prosthetics Clinic, Sendai, Japan

${ }^{3}$ Department of Nanomechanics, Tohoku University Graduate School of Engineering, Sendai, Japan.

${ }^{4}$ Division of Biomechanical Engineering, Tohoku University Graduate School of Biomedical Engineering, Sendai, Japan

*Corresponding Author: Kuniyuki Izumita, Division of Advanced Prosthetic Dentistry, Tohoku University Graduate School of Dentistry, Sendai, Japan.

Received: July 22, 2019; Published: August 14, 2019

DOI: $10.31080 /$ ASDS.2019.03.0615

\begin{abstract}
Objectives: The powder jet deposition (PJD) process is used for creation of hydroxyapatite (HA) layers on human teeth. The fabricated HA layers showed excellent microstructural and mechanical properties in vitro and in vivo. Titanium dioxide $\left(\mathrm{TiO}_{2}\right)$ changed the whiteness of the layers because of the selective reflection of light. This raises the possibility that $\mathrm{TiO}_{2}$ - $\mathrm{HA}_{\text {layer deposition may }}$ improve new whitening treatment for discolored teeth. For the development of new tooth whitening by PJD, the microstructural and mechanical properties of the $\mathrm{TiO}_{2}$-HA layers, particularly the effects of thermal stress, the color change obtained, and the color stability of the layers after thermal cycling were evaluated.
\end{abstract}

Materials and Methods: The microstructural properties of the $\mathrm{TiO}_{2}$-HA layers, namely surface thickness and roughness were evaluated from scanning electron microscopy (SEM) images and three-dimensional profiles. The mechanical properties were evaluated by micro-Vickers hardness and bonding strength tests. For color differences and stability, the CIE L*a*b* color system was used, and $\Delta \mathrm{E}^{*}$ values were calculated before and after the fabrication of the $\mathrm{TiO}_{2}$-HA layers. For visual color evaluation, images of specimens were taken with a digital camera. Furthermore, these material properties and color differences were evaluated before and after 500 thermal cycles $\left(5-55^{\circ} \mathrm{C}\right)$.

Results and Discussion: The $\mathrm{TiO}_{2}$-HA particles were packed densely in the layers, the maximum thickness of layers was about 60 $\mu \mathrm{m}$. There were no significant differences in surface roughness, hardness, or bonding strength before and after the thermal cycling. Moreover, these properties were equivalent to those of HA layers fabricated by PJD. The $\mathrm{TiO}_{2}$-HA layers had increased $\mathrm{L}^{*}$ and decreased $\mathrm{b}^{*}$ parameter compared with those of the enamel substrates, and the color difference $\Delta \mathrm{E}^{*}$ was about 6.7 units, indicating that $\mathrm{TiO}_{2}$-HA layers whitened the color of the treated tooth. Furthermore, it was confirmed from digital camera images that $\mathrm{TiO}_{2}$ - $\mathrm{HA}_{\mathrm{A}}$ layers showed visually perceptible level of whiteness. This color was maintained even after thermal cycling.

Conclusion: The fabrication of $\mathrm{TiO}_{2}$-HA layers by PJD may be a suitable new whitening treatment for discolored teeth.

Keywords: Powder Jet Deposition; Hydroxyapatite; Titanium Dioxide; Whitening; Discolored Teeth

Citation: Kuniyuki Izumita., et al. "Basic Research for New Tooth Whitening Applied the Powder Jet Deposition”. Acta Scientific Dental Sciences 3.9 (2019): 23-31. 


\section{Abbreviations}

PJD: Powder Jet Deposition; HA: Hydroxyapatite; $\mathrm{TiO}_{2}$ : Titanium dioxide; SEM: Scanning electron microscopy; $\mathrm{TiO}_{2}-\mathrm{HA}$ layers: $\mathrm{HA}$ layers containing $\mathrm{TiO}_{2}$ particles

\section{Introduction}

The self-esteem and professional relationships were influenced by the discolored teeth, white and light-colored teeth are regarded as important [1,2]. Tooth discoloration is classified by intrinsic or extrinsic factors (or a combination of both) according to etiology, and varies based on location, appearance, affinity to the tooth structure, and severity [3,4]. For removing the extrinsic discoloration, including chromogens with coffee, tea, cigarettes, or dental plaque, professional tooth polishing using abrasive compounds is generally used [1-5]. On the other hand, for treatment of teeth with intrinsic discoloration, that my be drug-related or caused by pulp tissue remnants after endodontic therapy or pulp necrosis, the bleaching with using radical agents or tooth restoration with conventional dental materials such as composite resin and porcelain are generally taken $[2,6]$. However, several studies showed side-effects of tooth bleaching agents, such as irritation of dental pulp, degreased enamel hardness, and tooth hypersensitivity $[7,8]$. Conversely, conventional restoration methods are well-established or developed, especially adhesive restoration [2], but require invasive excavation of tooth substance. Furthermore, the restorative materials used have quite different chemical and mechanical properties from those of tooth substance, enamel, and dentin, leading to clinical problems in the long run such as the loss of restorative materials from the tooth or secondary caries [9]. These observations suggest that the development of a novel method that provides a biomaterial interface layer with the tooth surface is necessary for the whitening treatment of tooth discoloration without invasion of the tooth substance and dental pulp.

In previous studies, the possibility of applying HA layer as a new restorative material with compositional, chemical and mechanical properties corresponding to those of tooth substance was presented [10-13]. The PJD is a precise mechanical coating technique with using ultrafine particles which accelerated to several hundred meters per second by the jet flow of carrier gas to fabricate functional surfaces with high efficiency. PJD is used at room temperature and atmospheric pressure, which enables it to be used with HA particles for the fabrication of HA layers on human teeth [10-13]. In in vitro studies showed that PJD technique can be used to fabricate thick HA layers on human enamel. These HA layers showed excellent microstructural and mechanical properties, including a micro-Vickers hardness equivalent to that of human enamel and a bonding strength almost equivalent to that of composite resin-enamel. These properties were not influenced by thermal stress [12]. Furthermore, PJD technique and fabricated HA layers showed high biocompatibility and safety in a preclinical trial [13].

$\mathrm{TiO}_{2}$ is a common additive in many pigments, personal care products, and other consumer products used in daily life. $\mathrm{TiO}_{2}$ based ingredients are mostly used as coloring agents in enamels, plastics, glazes, paper, foods, pharmaceuticals, cosmetics, and toothpastes [14]. $\mathrm{TiO}_{2}$ is also an important additive for dental composites, which must match the color of the natural tooth. $\mathrm{TiO}_{2}$ particles are non-toxic and stable in the oral environment and show high color stability over a long period [15]. According to a study carried out to determine the influence of $\mathrm{TiO}_{2}$ particles on the color, translucency, fluorescence, and opalescence of light curing composite resin, a concentration of $0.10-0.25 \% \mathrm{TiO}_{2}$ particles induced a whiter tooth color and simulated opalescence of human enamel [16]. In a study assessing the effect in terms of color stability of adding $\mathrm{TiO}_{2}$ nanoparticles to acrylic resin intended for the artificial sclera of ocular prostheses, the incorporation of $2.5 \% \mathrm{TiO}_{2}$ helped to maintain color stability after irradiation with ultraviolet light, simulating the aging of human eyes [17]. Furthermore, in this previous study, X-ray diffraction analyses confirmed that no new chemical compounds were generated from the $\mathrm{TiO}_{2}$ and $\mathrm{HA}$ particles. Therefore, the application of the HA layers containing $\mathrm{TiO}_{2}$ particles ( $\mathrm{TiO}_{2}$-HA layers) to the human tooth surface by PJD was proposed as a new whitening treatment for discolored teeth. The previous studies have led to an understanding of the excellent properties of HA layers fabricated by PJD. However, the properties of $\mathrm{TiO}_{2}$-HA layers have not yet been clarified. Furthermore, the degree to which $\mathrm{TiO}_{2}$-HA layers influence whitening and color stability have not been well documented. For the development of new whitening treatment system, the microstructural and mechanical properties of $\mathrm{TiO}_{2}$-HA layers before and after thermal cycling, and the color difference and color stability of the $\mathrm{TiO}_{2}-\mathrm{HA}$ layers were evaluated as a basic research. The null hypotheses of 
the present study were: (1) $\mathrm{TiO}_{2}$-HA layers could not be created by PJD process and would not demonstrate excellent microstructural and mechanical properties, (2) $\mathrm{TiO}_{2}$-HA layers would not whiten the tooth color, and (3) the material properties and white color of the $\mathrm{TiO}_{2}$-HA layers would not be maintained after thermal cycling.

\section{Materials and Methods}

Preparation of specimens and PJD process

Caries-free human molars extracted during orthodontic treatment were used in the present study, with the informed consent of the patients. All protocol and consent forms were approved by the Ethics Committee (approval number 25-10) of the Tohoku University Graduate School of Dentistry. The absence of caries was determined according to clinical parameters using a sharp explorer and visual inspection. The human molars were also checked by a diagnostic laser (DIAGNO dent, GC Co., Ltd. Tokyo, Japan) to make sure that no caries was present. The crown of each human molar was severed into lingual and buccal parts with using a diamond blade cutter. The buccal piece of the tooth was fixed onto the aluminum SEM stage using the epoxy resin-based adhesive agent. For present study, a flat enamel surface perpendicular to the enamel rods was prepared. To obtain an identical surface, the specimens were polished successively with 320-, 600-, 1000-, 1200-, 2000-, and 4000-grit silicon carbide grinding wheels with diamond paste, and the surface roughness was adjusted to about $0.4 \mu \mathrm{m}$ Ra. Before the experiment, the specimens were cleaned in an ultrasonic cleaning bath for $30 \mathrm{~min}$ and then dried in an air flow. The specimens were treated with PJD to fabricate $\mathrm{TiO}_{2}$-HA layers on their surfaces using $\mathrm{HA}^{-\mathrm{TiO}_{2}}$ particles synthesized by Sangi Co., Ltd. (Tokyo, Japan), to which $\mathrm{TiO}_{2}$ was added as a color regulator [13].

In the present study, the dental PJD device developed by Kuriyagawa and Sangi Co., Ltd. was used for fabrication of the $\mathrm{TiO}_{2}-\mathrm{HA}$ layers on the enamel substrate specimens (Figure 1). The blasting nozzle of the device was of a similar size to that of normal dental hand-pieces (Figure 2). The $\mathrm{HA}$ and $\mathrm{TiO}_{2}$ particles were mixed in the chamber of device with continuous flow of accelerated gas (air) and blasted from the nozzle onto the enamel substrate at room temperature $\left(25^{\circ} \mathrm{C}\right)$ and atmospheric pressure ( $\left.1 \mathrm{~atm}\right)$. Table 1 shows the details of the experimental conditions of the blasting.

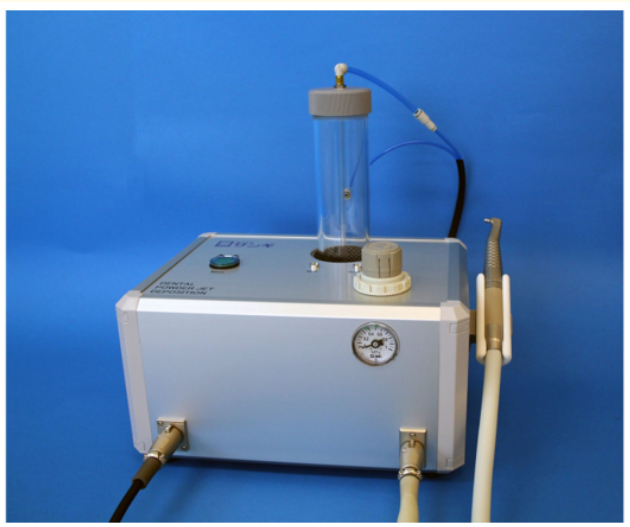

Figure 1: Dental hand-piece type PJD device.

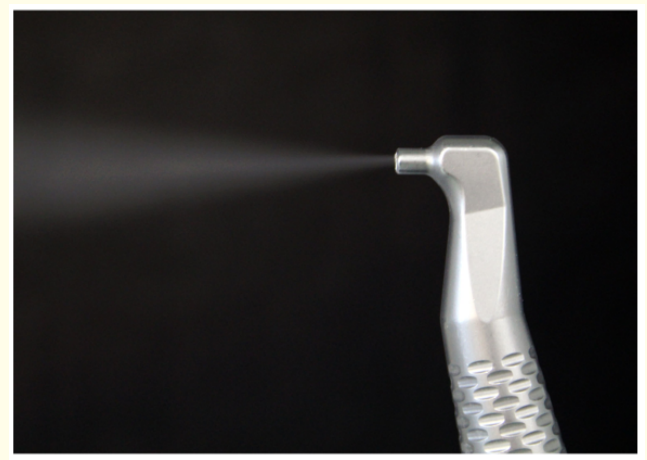

Figure 2: Blasting nozzle of PJD device.

\begin{tabular}{|l|l|}
\hline Substrate & Enamel \\
\hline Size of particles $\left(\right.$ containing $\mathrm{TiO}_{2)}(\mu \mathrm{m})$ & $3.0 \pm 1.0$ \\
\hline Accelerated gas pressure $(\mathrm{MPa})$ & 0.5 \\
\hline Feed gas pressure $(\mathrm{MPa})$ & 0.5 \\
\hline Blasting angle $\left(^{\circ}\right)$ & 90 \\
\hline Blasting time $(\mathrm{s})$ & 30 \\
\hline Nozzle scan rate $(\mathrm{mm} / \mathrm{s})$ & 5 \\
\hline Gap between nozzle and substrate $(\mathrm{mm})$ & 1.0 \\
\hline
\end{tabular}

Table 1: The details of the experimental conditions of the PJD blasting. 
Specimens were fixed on the stage, with their enamel surface perpendicular to the blasting nozzle. Each specimen was blasted using a fixed time and nozzle scan rate, overlapping about 15 times, to fabricate $\mathrm{TiO}_{2}$-HA layers with an area of about $3.5 \mathrm{~mm} \times$ $3.5 \mathrm{~mm}$. After the deposition, the layers were polished by diamond polishing paste (Dia Polisher Paste, GC Co., Ltd., Tokyo, Japan) and a felt wheel for $30 \mathrm{~s}$ with a pressure of $5000 \mathrm{~g}$ [12].

\section{Thermal cycling}

Two-temperature computer-controlled thermal cycler (Thermal cycling K-179; Tokyo-Giken Co., Ltd., Tokyo, Japan) was used. The two water baths of the thermal cycler were maintained at $5^{\circ} \mathrm{C}$ and $55^{\circ} \mathrm{C}$. Each cycle is consisted of $20 \mathrm{~s}$ immersion in each water bath and a travel time of $10 \mathrm{~s}$. The water baths were constantly stirred by stirrers, and the variation in the temperature of each water bath remained within $1^{\circ} \mathrm{C}$ of the set temperature. The specimens were immersed in distilled water at $37^{\circ} \mathrm{C}$ for 1 day. Following this immersion, the specimens were subjected to 500 thermal cycles $[12,18]$.

\section{Evaluation of microstructural and mechanical properties}

The cross-section of the $\mathrm{TiO}_{2}$-HA layers was observed by SEM (JSM-6500F, JEOL Co., Ltd., Tokyo, Japan) for evaluation of their microstructure. The three-dimensional profiles, including surface thickness and roughness, of the layers were evaluated by three-dimensional non-contact measurement system (NH-3, Mitaka Kohki Co., Ltd., Tokyo, Japan). For evaluation of the mechanical properties, micro-Vickers hardness was measured by dynamic micro-hardness tester (FM-ARS 9000, Future-Tech Co., Ltd. Kawasaki, Japan). A load of $100 \mathrm{gf}$ was applied for $5 \mathrm{~s}$ with a pyramid-shaped die; the depth of the resulting impression was used to calculate the hardness of the specimens $[12,19]$. Furthermore, the bonding strength of the layers to the enamel substrates was evaluated by micro-tensile test (Romulus, Quad Group, Spokane, WA, USA) [12,20]. An epoxy precoated alumina stud was prepared perpendicularly onto the surface of the specimen. The area of the surface coated with the epoxy glue was about $2.7 \mathrm{~mm}$ in diameter. The specimen was set into the machine and gripped after curing at $150^{\circ} \mathrm{C}$ for $1 \mathrm{~h}$. The stud was pulled until destruction of the specimen occurred, and the bonding strength was determined to be the maximum load recorded [12]. SEM images, three-dimensional profiles, surface thickness and roughness for microstructural properties, and micro-Vickers hardness and bonding strength for mechanical properties were evaluated before and after the above-mentioned thermal cycling.

\section{Evaluation of color difference and stability}

The color of the specimens was measured according to the CIE $\mathrm{L}^{*} \mathrm{a}^{*} \mathrm{~b}^{*}$ color scale relative to the standard illuminant D65 and using a $10^{\circ}$ observer on a spectrophotometer (CMS-35FS/C, Murakami Color Research Laboratory Co., Ltd., Tokyo, Japan) at wavelengths of 390-730 nm in reflectance mode [13]. The CIE L*a*b* system is composed of three axes or coordinates: $\mathrm{L}^{*}$ (lightness, from $0=$ black to $100=$ white), $\mathrm{a}^{*}$ (from $-\mathrm{a}=$ green to $+\mathrm{a}=$ red) and $\mathrm{b}^{*}$ (from $-b=$ blue to $+b=$ yellow) $[21,22]$. The area of irradiation and color measurement was $\varphi 6 \mathrm{~mm}$ and $\varphi 3 \mathrm{~mm}$, respectively. The areas of TiO2-HA layers and the control HA layers were set to be wider than the spectrophotometer measurement area. Each specimen was chromatically measured three times under different conditions (1) before and (2) after the fabrication of the layers, and (3) after the thermal cycling - and the average values were calculated. Total color difference between the above-mentioned three conditions were calculated by the following equation:

$$
\Delta E^{*}=\sqrt{\left(\Delta L^{*}\right)^{2}+\left(\Delta a^{*}\right)^{2}+\left(\Delta b^{*}\right)^{2}}
$$

For evaluation of the degree of whitening, the color difference between conditions (1) and (2) was calculated as $\Delta \mathrm{E}^{*}{ }_{1}$. For evaluation of the color stability, the difference between conditions (2) and (3) was calculated as $\Delta \mathrm{E}^{*}$. Furthermore, images of the $\mathrm{TiO}_{2}$-HA layers at the above-mentioned three conditions were obtained by digital camera (Nikon D70S, Nikon Co., Ltd., Tokyo, Japan) for visual evaluation of the color difference and color stability.

\section{Statistical analysis}

The Mann-Whitney U-test was used to detect significant differences in surface roughness, micro-Vickers hardness and bonding strength before and after thermal cycling. For evaluation of color difference and stability, the Turkey-Kramer test was used for the among-group comparison. The IBM SPSS Statistics software version 25 (Japan IBM Co., Ltd, Tokyo, Japan) was used for statistical analysis, and the significance level was set at 0.05 .

\section{Results and Discussion}

\section{Microstructural and mechanical properties}

Figure 3 shows cross-sectional SEM images of the $\mathrm{TiO}_{2}-\mathrm{HA}$ layers and the enamel substrate before and after the thermal cycling. There were no cracks or pores in the layers, indicating the deposition of fully dense $\mathrm{TiO}_{2}$-HA layers. Furthermore, there were no observable gaps between the layer and the enamel substrate. In a 
previous study on the microstructure of a plasma-sprayed $50 \mu \mathrm{m}$ thick HA coating on titanium alloy, cross-sectional SEMs revealed the presence of cracks in the titanium alloy and along the HA coating-substrate interface [23]. Such cracks may directly influence the bonding strength and may affect the long-term stability of such HA coatings $[23,24]$. Although the substrate was different, it could be considered HA layers with excellent material properties are more effectively fabricated using PJD process than the above-mentioned plasma spray coating technique.

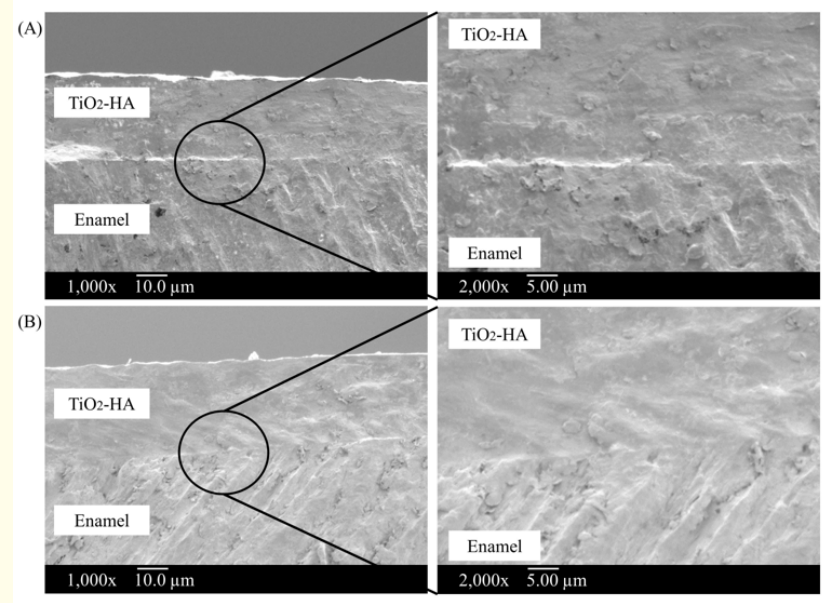

Figure 3: SEM images of the cross-section of $\mathrm{TiO}_{2}$-HA layer before (A) and after (B) thermal-cycling.

Figure 4 shows three-dimensional view of the fabricated $\mathrm{TiO}_{2}$ HA layers. Under the present conditions, the maximum and average thickness were about $60 \mu \mathrm{m}$ and $50 \mu \mathrm{m}$, respectively. In a previous study, the maximum and average thicknesses of HA layers fabricated on enamel substrates by PJD on the same experimental conditions were also about $60 \mu \mathrm{m}$ and $50 \mu \mathrm{m}$, respectively [12]. It was expected that the present $\mathrm{TiO}_{2}$-HA layers would show almost the same microstructural properties and high stability as those of the previous HA layers.

Table 2 shows the average surface roughness, the micro-Vickers hardness, and the bonding strength of the layers. The surface of $\mathrm{TiO}_{2}$-HA layers polished smoothly by diamond polishing paste, and their surface roughness was almost equal to that of the HA layers in the previous study [12]. It is well known that smoothly pol- ished dental restorations show high aesthetic quality and compatibility compared with rougher surface restorations in oral cavities $[25,26]$. Studies investigating the surface roughness of dental composite resin have reported that Ra values above $0.2 \mu \mathrm{m}$ may lead to increased periodontal inflammation, plaque accumulation, and greater stain absorption than relatively smooth surfaces [27-29]. According to a review of the literature, the roughness of enamel surfaces in the oral cavity influences initial bacterial adhesion, and plaque tends to accumulate more on surface irregularities such as cracks, grooves, or abrasion defects on enamel [30]. Therefore, the present $\mathrm{TiO}_{2}$-HA layers were expected to show low bacterial adhesion, low plaque accumulation, and low stain absorption after polishing because they had a much lower Ra than those reported in other similar studies.
(A)

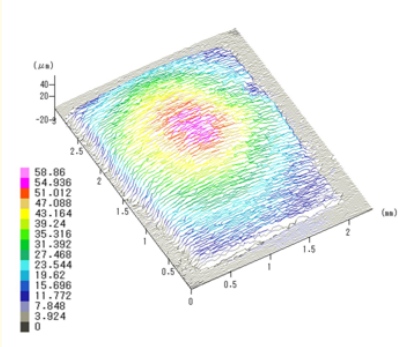

(B)

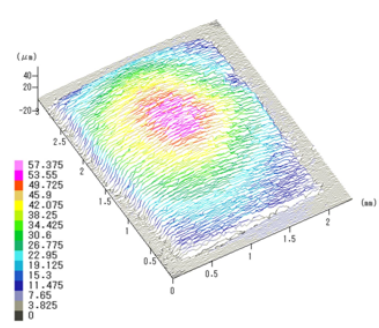

Figure 4: Three-dimensional view of $\mathrm{TiO}_{2}-\mathrm{HA}$ layer fabricated on enamel substrate before (A) and after (B) thermal cycling.

\begin{tabular}{|c|c|c|c|}
\hline $\begin{array}{l}\text { Evaluation } \\
\text { items }\end{array}$ & $\begin{array}{c}\text { Before thermal } \\
\text { cycling }\end{array}$ & $\begin{array}{c}\text { After thermal } \\
\text { cycling }\end{array}$ & P-value \\
\hline $\begin{array}{l}\text { Surface rough- } \\
\text { ness }(\mu \mathrm{m})^{a}\end{array}$ & $0.0774(0.025)$ & $0.0793(0.030)$ & $0.946^{b}$ \\
\hline $\begin{array}{l}\text { Micro-Vickers } \\
\text { hardness (Hv) }^{\text {a }}\end{array}$ & 371.38 (20.68) & $365.6(27.53)$ & $0.496^{b}$ \\
\hline $\begin{array}{l}\text { Bonding } \\
\text { strength }(\mathrm{MPa})^{\text {a }}\end{array}$ & $15.71(1.48)$ & $15.49(3.82)$ & $0.791^{b}$ \\
\hline
\end{tabular}

${ }^{\text {a }}$ Data are shown as mean (standard deviation).

${ }^{\text {b }}$ By Mann-Whitney $U$-test.

Table 2: Surface roughness, micro-Vickers hardness and bonding strength of $\mathrm{TiO}_{2}$-HA layers before and after thermal cycling. $(n=10)$. 
With regard to the micro-Vickers hardness and bonding strength, these results are also almost the same as those obtained for the HA layers fabricated on enamel under the same PJD conditions in the previous study [12]. Furthermore, several studies have showed composite resin to enamel substrate bonding strengths of 5.9 to $22.2 \mathrm{MPa}$; these values are similar to the $15 \mathrm{MPa}$ bonding strength measured for the present $\mathrm{TiO}_{2}$-HA layers [31-33]. Thus, it was confirmed that the PJD process could fabricate $\mathrm{TiO}_{2}-\mathrm{HA}$ layers with excellent material properties on enamel substrates. Furthermore, the above results indicate that included $\mathrm{TiO}_{2}$ particles did not influence the layer fabrication process or the material properties of the HA. Therefore, the first null hypothesis was rejected.

\section{Color difference}

The color difference results of the $\mathrm{TiO}_{2}$-HA layers and HA layers are shown in Table 3 and Table 4, and digital camera images are shown in Figure 5. The $\mathrm{TiO}_{2}$-HA layers, between conditions (1) and (2), and (1) and (3), the L* parameter significantly increased, the $\mathrm{b}^{*}$ parameter significantly decreased, and the $\mathrm{a}^{*}$ parameter did not change. In contrast, none of the parameters significantly changed between any of the conditions for the HA layers. These results indicated that the fabricated $\mathrm{TiO}_{2}$-HA layer whitened the color of the specimens; their color became slightly bluer. Furthermore, the results suggested that the HA layers were whitened by the addition of $\mathrm{TiO}_{2}$ particles. Previous studies that have evaluated whitening effects in vitro have reported that whitening occurs mainly by increasing the $\mathrm{L}^{*}$ parameter (higher $\mathrm{L}^{*}$ ), reducing yellowness (lower $\mathrm{b}^{*}$ ) and, to a lesser extent, reducing redness (lower $\mathrm{a}^{*}$ ) [2,34]. According to a review of the literature1, the subjective responses to whiteness improvement and satisfaction are significantly correlated with changes in the $\mathrm{b}^{*}$ parameter and not the $\mathrm{L}^{*}$ or $\mathrm{a}^{*}$ parameters, and the yellow-blue shift is perceptual importance in tooth whitening [1]. The reason for the color change observed in the present study might be related to selective reflection and absorption of incident light by the $\mathrm{TiO}_{2}$ particles. The total color differences $\Delta \mathrm{E}^{*}$ of the $\mathrm{TiO}_{2}$-HA layers and HA layers, which evaluate the degree of whitening, were about 6.7 units and 0.5 units, respectively. Several reports showed the threshold levels of total color difference which can be visually perceived [35,36]. In a study of intraoral determination of perceptibility and acceptability tolerances for shade mismatch, the color difference of the test denture which $50 \%$ of dentists could perceive was 2.6 units, while the value at which $50 \%$ of dentists would remake the denture owing to color mismatch was 5.5 units [36]. The digital camera images (Figure 5) clearly confirmed that the $\mathrm{TiO}_{2}$-HA layers showed a visually perceptible level of whiteness. This indicated that the $\mathrm{TiO}_{2}$ particles contributed to the whitening of the HA layers. Therefore, the second null hypothesis was also rejected. However, the present $\mathrm{TiO}_{2}-$ HA layers significantly whitened the enamel substrates beyond the perceptible threshold level, their color was too whitening and mismatched the optical properties of natural teeth.

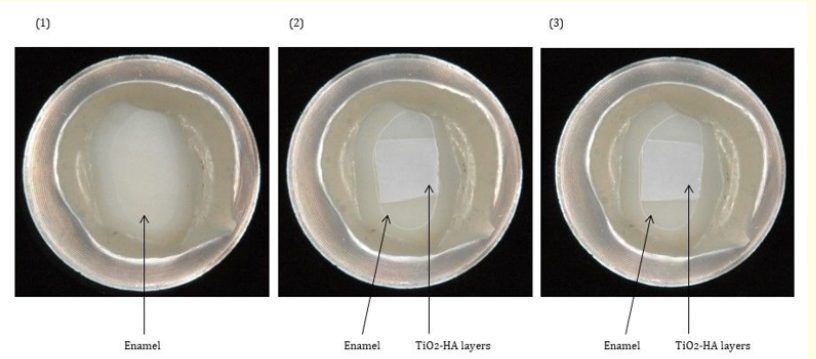

Figure 5: Digital camera images of $\mathrm{TiO}_{2}$-HA layers before (1) and after fabrication (2), and after thermal cycling (3).

\begin{tabular}{|l|c|c|c|c|c|}
\hline & Color parameter & (1) Before fabrication & (2) After fabrication & (3) After thermal cycling & P-value \\
\hline \multirow{3}{*}{$\mathrm{TiO}_{2}-\mathrm{HA}^{\mathrm{a}}$} & $\mathrm{L}^{*}$ & $71.02(1.81)^{\mathrm{c}, \mathrm{d}}$ & $77.27(1.36)^{\mathrm{c}}$ & $76.73(1.43)^{\mathrm{d}}$ & $<0.001^{\mathrm{b}}$ \\
\cline { 2 - 6 } & $\mathrm{a}^{*}$ & $-2.25(0.28)$ & $-2.33(0.35)$ & $-2.25(0.31)$ & $0.537^{\mathrm{b}}$ \\
\cline { 2 - 6 } & $\mathrm{b}^{*}$ & $-1.54(0.23)^{\mathrm{c}, \mathrm{d}}$ & $-3.73(0.46)^{\mathrm{c}}$ & $-3.72(0.42)^{\mathrm{d}}$ & $<0.001^{\mathrm{b}}$ \\
\hline \multirow{2}{*}{$\mathrm{HA}^{\mathrm{a}}$} & $\mathrm{L}^{*}$ & $70.11(0.91)$ & $70.60(1.00)$ & $70.33(0.89)$ & $0.121^{\mathrm{b}}$ \\
\cline { 2 - 6 } & $\mathrm{a}^{*}$ & $-2.38(0.33)$ & $-2.44(0.35)$ & $-2.41(0.37)$ & $0.835^{\mathrm{b}}$ \\
\cline { 2 - 6 } & $\mathrm{b}^{*}$ & $-1.43(0.20)$ & $-1.44(0.20)$ & $-1.45(0.22)$ & $0.932^{\mathrm{b}}$ \\
\hline
\end{tabular}

${ }^{a}$ Data are shown as mean (standard deviation).

${ }^{\mathrm{b}}$ By Turkey-Kramer test.

"Significant within-group difference between "(1) Before fabrication” and “(2) After fabrication” by Turkey-Kramer test.

d Significant within-group difference between “(1) Before fabrication” and “(3) After thermal cycling” by Turkey-Kramer test.

Table 3: The results of color parameters of $\mathrm{TiO}_{2}$-HA and HA layers before (1) and after fabrication (2), and after thermal cycling. ( $\mathrm{n}=10$ ) 


\begin{tabular}{|l|c|c|}
\hline & $\boldsymbol{\Delta E}_{\mathbf{1}}^{*}$ & $\boldsymbol{\Delta} \mathbf{E}_{\mathbf{2}}^{*}$ \\
\hline $\mathrm{TiO}_{2}$-HA & $6.67(1.48)$ & $0.75(0.65)$ \\
\hline $\mathrm{HA}$ & $0.54(0.23)$ & $0.34(0.23)$ \\
\hline
\end{tabular}

Table 4: Total color differences of the $\mathrm{TiO}_{2}$ - $\mathrm{HA}$ and HA layers. $(n=10)$

\section{Material and color stability}

Thermal cycling simulated the frequent changes in intra-oral temperature induced by drinking, eating, and breathing in the present study. Thermal stresses are related to the mechanical stresses; differential thermal changes can induce crack propagation through bonded interfaces. The changes of gap dimensions result in volume changes which pump pathogenic oral fluids in and out of the gaps [37-40]. In the present study, thermal cycling between $5^{\circ} \mathrm{C}$ and 55 ${ }^{\circ} \mathrm{C}$ for 500 cycles based on the International Organization for Standardization specifications for evaluation of dental materials durability was adopted to evaluate the $\mathrm{TiO}_{2}$-HA layers under the same conditions as those used for the HA layers in the previous study [12].

Figure 3 and 4 shows the $\mathrm{TiO}_{2}$-HA layers maintained their threedimensional morphology even after thermal cycling. Table 2 shows that there were no significant differences in the surface roughness, micro-Vickers hardness, and bonding strength of the layers before and after thermal cycling. The results of color difference of the $\mathrm{TiO}_{2}$-HA layers (Table 3 and 4) confirmed that no significant changes in any of the color parameters occurred after thermal cycling; although a color difference $\Delta \mathrm{E}^{*}{ }_{1}$ was observed, while $\Delta \mathrm{E}^{*}{ }_{2}$ was negligible in the present study. Similarly, for the HA layers, there were no significant differences in any of the color parameters, and $\Delta \mathrm{E}^{*}{ }_{2}$ was also negligible. Visual evaluation by digital camera images (Figure 5) revealed no differences in the color of the layers before and after the thermal cycling. In a previous investigation on the color stability of three light-polymerized veneer materials exposed to xenon light to simulate several years of clinical use, the obtained $\Delta \mathrm{E}^{*}$ values of lower than approximately 3.3 units were considered to indicate high color stability [35]. Thus, the $\mathrm{TiO}_{2}$-HA layers not only whitened the enamel substrates but also maintained their whiteness after thermal cycling. As a result, the third null hypothesis was also rejected.

In conclusion, the PJD process was used to fabricate a thick $\mathrm{TiO}_{2}$ HA layers on human enamel substrates. The layers demonstrated and maintained excellent microstructural and mechanical properties comparable to those of the HA layers in the previous study even after thermal cycling simulated the oral environment. Furthermore, it was confirmed that the $\mathrm{TiO}_{2}$-HA layers whitened the color of the tooth surface and showed high color stability even after thermal cycling. However, the whiteness of the layers mismatched the natural tooth color to too great an extent. One of the major goals in esthetic dentistry is to produce restorations that match the properties of natural teeth [1]. It has been reported that adjusting the concentration of $\mathrm{TiO}_{2}$ particles to be added to the composite resin makes it possible to control the dental shade [16]. Thus, adjusting the ratio of $\mathrm{TiO}_{2}$ particles to HA particles used in the present PJD process could be used to fabricate layers matching natural tooth shades, as patients desire. Whether layers containing adjusted concentrations of $\mathrm{TiO}_{2}$ will demonstrate the same excellent material properties is unclear but warrants examination. Furthermore, the present PJD process could be applicable to particularly discolored teeth because the $\mathrm{TiO}_{2}$-HA layers showed a perceptible white color. However, it is unknown whether this process could be applied to tooth substrate with quantitative enamel deficiencies such as amelogenesis imperfecta, because the present study is based on the results of layers fabricated on sound enamel substrate. It is necessary to verify the layer formability on amelogenesis imperfecta affected tooth substrates, for example, on which most of the enamel has been chipped away or worn off, exposing large areas of dentin with yellowish-brown discoloration [41]. Achieving this would increase the potential of the PJD process for clinical use as a new whitening treatment for intrinsic tooth discoloration.

\section{Conclusion}

Within the limitations of the present study, it was concluded that a PJD process can be used to fabricate thick $\mathrm{TiO}_{2}$-HA layers on enamel substrates. The $\mathrm{TiO}_{2}$-HA layers demonstrated excellent microstructural and mechanical properties comparable to those of PJD fabricated HA layers, even after a thermal cycling. Furthermore, the $\mathrm{TiO}_{2}$-HA layers whitened the tooth color and exhibited high color stability. The fabrication of $\mathrm{TiO}_{2}-\mathrm{HA}$ layers by PJD may be a valuable new whitening treatment for discolored teeth.

\section{Acknowledgements}

The present work was supported by Sangi Co., Ltd. (Tokyo, Japan) for expert technical assistance. The present study received no external funding to conduct this research through any of the authors involved. 


\section{Conflict of Interest}

The authors have no conflicts of interest.

\section{Bibliography}

1. Joiner A. "Tooth colour: a review of the literature". Journal of Dentistry 32 (2004): 3-12.

2. Lima FG., et al. "In vitro evaluation of the whitening effect of mouth rinses containing hydrogen peroxide". Brazilian Oral Research 26.3 (2012): 269-274.

3. Dahl JE and Pallesen U. "Tooth bleaching-a critical review of the biological aspects". Critical Reviews in Oral Biology and Medicine 14.4 (2003): 292-304.

4. Hattab FN., et al. "Dental discoloration: an overview". Journal of Esthetic Dentistry 11.6 (1999): 291-310.

5. Watts A and Addy M. "Tooth discoloration and staining: a review of the literature". British Dental Journal 190.6 (2001): 309-316.

6. Plotino G., et al. "Nonvital tooth bleaching: a review of the literature and clinical procedures". Journal of Endodontics 34.4 (2008): 394-407.

7. Hannig C., et al. "Determination of peroxides in saliva-kinetics of peroxide release into saliva during home-bleaching with Whitestrips and Vivastyle". Archives of Oral Biology 48.8 (2003): 559-566.

8. Azer SS., et al. "Effect of bleaching on tooth discoloration from food colourant in vitro". Journal of Dentistry 39.3 (2011): 5256.

9. Mjor IA. "Clinical diagnosis of recurrent caries". Journal of the American Dental Association 136.10 (2005) :1426-1433.

10. Akatsuka R., et al. "Characteristics of hydroxyapatite film formed on human enamel with the powder jet deposition technique". Journal of Biomedical Materials Research Part B Applied Biomaterials 98.2 (2011): 210-216.

11. Akatsuka R., et al. "Effect of Hydroxyapatite film formed by powder jet deposition on dentin permeability". European Journal of Oral Sciences 120 (2012) :558-562.

12. Akatsuka R., et al. "Evaluation of thermal stress in hydroxyapatite film fabricated by powder jet deposition". European Journal of Oral Sciences 121.5 (2013): 504-507.
13. Akatsuka R., et al. "Exploratory trial to evaluate the hydroxyapatite layer formed by a new dental treatment system". Open Journal of Stomatology 5.12 (2015): 281-286.

14. Periasamy VS., et al. "Effects of titanium dioxide nanoparticles isolated from confectionery products on the metabolic stress pathway in human lung fibroblast cells". Archives of Environmental Contamination and Toxicology 68.3 (2015): 521-533.

15. Klapdohr S and Moszner N. "New inorganic components for dental filling composites". Monatshefte fur Chemie 136.1 (2005): 21-45.

16. Yu B., et al. "Influence of $\mathrm{TiO} 2$ nanoparticles on the optical properties of resin composites". Dental Materials 25.9 (2009): 1142-1147.

17. Andreotti AM., et al. "Influence of nanoparticles on color stability, microhardness, and flexural strength of acrylic resins specific for ocular prosthesis". International Journal of Nanomedicine 10.9 (2014): 5779-5787.

18. Weir MD., et al. "Nanocomposite containing CaF (2) nanoparticles: thermal cycling, wear and long-term water-aging". Dental Materials 28.6 (2012): 642-652.

19. Hahnel S., et al. "Two-body wear of dental restorative materials". Journal of the Mechanical Behavior of Biomedical Materials 4.3 (2011): 237-244.

20. International Organization for Standardization. "ISO/TR 11405 Dentistry-guidance on testing of adhesion to tooth structure". Geneva: International Organization for Standardization (1994): 1-14.

21. CIE (Commission International de l'Eclairage). "Colorimetry, Technical Report”. CIE Pub 2nd edition., Vienna, Austria; Bureau Central de la CIE (1986): 12.

22. Park MY., et al "Influence of fluorescent whitening agent on the fluorescent emission of resin composites". Dental Materials 23.6 (2007): 731-735.

23. Carrado A. "Structural, microstructural, and residual stress investigations of plasma-sprayed hydroxyapatite on Ti-6Al-4 V". ACS Applied Materials and Interfaces 2.2 (2010): 561-565.

24. Garcia-Sanz FJ., et al. "Hydroxyapatite coatings: a comparative study between plasma-spray and pulsed laser deposition techniques". Journal of Materials Science. Materials in Medicine 8.12 (1997): 861-865. 
25. Weitman RT and Eames WB. "Plaque accumulation on composite surface after various finishing procedures". Journal of the American Dental Association 91.1 (1975): 101-106.

26. Strassler HE and Bauman G. "Current concepts in polishing composite resins". Practical Periodontics and Aesthetic Dentistry 5.3 (1993): 12-17.

27. Bollen CM., et al. "Comparison of surface roughness of oral hard materials to threshold surface roughness for bacterial plaque retention: a review of the literature". Dental Materials 13.4 (1997): 258-269.

28. Kumari RV., et al. "Evaluation of the effect of surface polishing, oral beverages and food colorants on color stability and surface roughness of nanocomposite resins". Journal of International Oral Health 7.7 (2015): 63-70.

29. Ruttermann S., et al. "Bacterial viability and physical properties of antibacterially modified experimental dental resin composutes". PLoS One 8.11 (2013): e79119.

30. Quirynen M and Bollen CM. "The influence of surface roughness and surface-free energy on supra- and subgingival plaque formation in man. A review of the literature". Journal of Clinical Periodontology 22.1 (1995):1-14.

31. Eminkahyagil N., et al. "Sealant and composite bond strength to enamel with antibacterial/self-etching adhesives". International Journal of Paediatric Dentistry 15.4 (2005): 274-281.

32. Kameyama A., et al. "Tensile bond strength of one-step selfetch adhesives to Er:YAG laser-irradiated and non-irradiated enamel". Dental Materials Journal 27.3 (2008): 386-391.

33. Turkun M and Kaya AD. "Effect of $10 \%$ sodium ascorbate on the shear bond strength of composite resin to bleached bovine enamel". Journal of Oral Rehabilitation 31.12 (2004): 11841191.

34. International Commission of Illumination. "Recommendations on uniform colour spaces, color difference equations and psychometric colour terms". CIE Publication 15.2 (1978).

35. Ruyter IE and Moller B. "Color stability of dental composite resin materials for crown and bridge veneers". Dental Materials 3.5 (1987): 246-251.
36. Dougla RD., et al. "Intraoral determination of the tolerance of dentists for perceptibility and acceptability of shade mismatch". The Journal of Prosthetic Dentistry 97.4 (2007): 200208.

37. Asaka Y., et al. "Influence of thermal cycling on dentin bond strengths of single-step self-etch adhesive systems". Operative Dentistry 32.1 (2007): 73-78.

38. Saboa VP., et al. "Analysis of differential artificial ageing of the adhexive interface produced by a two-step etch-and-rinse adhexive". European Journal of Oral Sciences 117.5 (2009): 618624.

39. Krejci I., et al. "Resin composite shrinkage and marginal adaptation with different pulse-delay light curing protocols". European Journal of Oral Sciences 113.6 (2005): 531-536.

40. Gale MS and Darvell BW. "Thermal cycling procedures for laboratory testing of dental restorations". Journal of Dentistry 27.2 (1999): 89-99.

41. Hiraishi N., et al. "Effect of acid etching time on bond strength of an etch-and-rinse adhesive to primary tooth dentine affected by amelogenesis imperfecta". International Journal of Paediatric Dentistry 18.3 (2008): 224-230.

\section{Volume 3 Issue 9 September 2019}

(C) All rights are reserved by Kuniyuki Izumita., et al. 